\title{
Labour productivity and regional labour markets resilience in Europe
}

\author{
Elias Giannakis ${ }^{1}$ D $\cdot$ Theofanis P. Mamuneas ${ }^{2}$
}

Received: 2 April 2021 / Accepted: 8 December 2021 / Published online: 30 January 2022

(c) The Author(s), under exclusive licence to Springer-Verlag GmbH Germany, part of Springer Nature 2021

\begin{abstract}
This paper conceptualizes and empirically explores the resilience of European Union regional labour markets in terms of labour productivity growth. We assess the effect of pre-crisis region-specific factors on regional labour markets resilience controlling for the effect of exogenous technological change and substitution between capital and labour. Regional input-output models are developed to estimate supplies and sales linkages across the European Union NUTS-2 regional economies. Spatial Durbin Error Model estimates suggest that regional labour markets characterised by a higher level of economic pull capabilities of the Construction sector and a higher level of industrial concentration can better withstand the effects of the negative shock and recover faster. Place-based policies building on regions' competitive strengths can smooth out the negative effect of the economic shock and accelerate the recovery of regional labour markets, while policy interventions promoting capital investment can further enhance labour productivity in European Union regions.
\end{abstract}

JEL Classification C67 $\cdot \mathrm{E} 24 \cdot \mathrm{R} 11 \cdot \mathrm{R} 12 \cdot \mathrm{R} 15$

\section{Introduction}

The spatial labour markets have experienced great volatility and uncertainty during the last two decades. The severe and asymmetric territorial impacts of the recent financial, political and health events across local labour markets, from the Great Recession to Brexit and the current corona pandemic crisis, have provided new

Elias Giannakis

e.giannakis@cyi.ac.cy

Theofanis P. Mamuneas

tmamuneas@ucy.ac.cy

1 Energy Environment and Water Research Center, The Cyprus Institute, 20 Konstantinou Kavafi Street, 2121 Nicosia, Cyprus

2 Department of Economics, University of Cyprus, P.O. Box 20537, 1678 Nicosia, Cyprus 
stimuli to regional scientists to understand the varying ability of spatial labour markets to withstand, react and recover from exogenous shocks.

Several methodologies have been developed to explore the resilience of regional labour markets to external perturbations, ranging from short-term responses to absorb an external shock (Giannakis and Bruggeman 2017a) to long-term adaptability to develop new growth paths (Pontarollo and Serpieri 2020a). The increasing use of the notion of resilience in analysing spatial labour markets performance, as in other fields of application, has brought more clarity on the definition of the concept, but no consensus has yet been reached (Boschma 2015). The theorization and subsequently the empirical operationalization of the resilience concept is still under development (Martin and Sunley 2015; Tsiapa et al. 2018).

Local labour markets resilience features are usually measured in terms of employment growth rates, either absolute or relative, e.g., versus EU average (Lagravinese 2015; Giannakis and Bruggeman 2017b). Several studies suggest that labour productivity is positively associated with employment, i.e., higher labour productivity growth induces lower unemployment rates (Mortensen and Pissarides 1998; Miyamoto and Takahashi 2011). In this study, we conceptualize and measure the resilience of regional labour markets in terms of labour productivity growth, which is equal to regional economic output growth minus the labour input growth.

The behaviour of labour productivity has been widely studied both across European regions (Cuadrado-Roura et al. 2000; Ezcurra et al. 2007) and within individual countries, e.g., across Italian (Giacinto and Nuzzo 2006), British (Gardiner et al. 2020) and Greek (Christopoulos and Tsionas 2004) regions. Filippetti and Peyrache (2015) assessed the role of the technology gap, capital deepening, exogenous technical change, and efficiency change in explaining labour productivity differences in European regions. Basile et al. (2008) analysed the relationship between regional unemployment, wages, and labour productivity differentials in Europe. Tsiapa et al. (2018) explored how EU regions' pre-crisis path-dependence productivity changes influenced their resilience levels during the economic crisis period, 2008-2013.

Our resilience concept compares the labour productivity growth rate of a regional labour market to the labour productivity growth rate of a reference regional labour market. Region-specific characteristics and growth paths before the onset of the economic downturn have been found to strongly affect the performance of spatial labour markets during and after exogenous shocks (Di Caro and Fratesi 2018). Our framework aims to consistently estimate the effect of pre-crisis conditions on the resilience of spatial labour markets, controlling for the effect of exogenous technological change and substitution of labour with capital.

Various region-specific factors have been linked to the ability of spatial labour markets to resist negative exogenous shocks (Crescenzi et al. 2016). However, little research has been conducted on the role of industrial linkages and interdependencies in shaping spatial labour markets resilience capabilities. The industrial structure of a region has been considered a major determinant for the resilience of regional labour markets to external perturbations (Cainelli et al. 2019a). A major area of debate has been whether a diverse economic structure provides greater regional resilience to negative exogenous shocks than a more specialised structure (Martin 2012; Martin and Sunley 2015). However, precisely how a diversified or specialised regional 
economy reacts to recession strongly depends on the degree of direct and indirect sectoral interdependencies (Martin 2012).

Input-output (IO) models have been applied in the regional resilience literature to analyse the interdependence of economic sectors and simulate how an exogenous shock propagates in spatial economies through supplies and sales linkages (Acemoglu et al. 2016; Galbusera and Giannopoulos 2018). However, most of the applications have been employed in individual countries. For instance, IO models have been employed to explore the resilience of regional labour markets to economic shocks in the Netherlands (Diodato and Weterings 2015), the UK (Kitsos et al. 2019), and Greece (Giannakis and Bruggeman 2017a).

The contribution of the paper is twofold. First, we develop a theoretical model, which is based on the theory of production, for the operationalization and empirical measurement of regional labour markets resilience. Second, we empirically explore the relationship between a set of pre-crisis region-specific factors, namely, industrial interconnectedness, industrial concentration, agglomeration economies and human capital factors, and the ability of labour markets to resist and recover from the impact of exogenous shocks. Industrial interconnectedness indicators are not available at the regional level, thus we constructed regional input-output models to estimate sectoral backward and forward linkages across the European Union (EU) NUTS-2 regions.

\section{Theoretical model}

We define labour productivity growth of a region $i$ as the logarithmic ratio of output produced to labour at period $t$ over the ratio of output produced to labour at period $t-s$ as follows:

$$
\ell_{\mathrm{it}}=\ln \frac{\frac{y_{\mathrm{it}}}{L_{\mathrm{it}}}}{\frac{y_{\mathrm{it}-s}}{L_{\mathrm{it}-s}}}=\ln \frac{y_{\mathrm{it}}}{y_{\mathrm{it}-s}}-\ln \frac{L_{\mathrm{it}}}{L_{\mathrm{it}-s}}
$$

where $y_{i t}, L_{i t}$ are the output and labour input of region $i$ at period $t$, respectively.

Equation (1) defines labour productivity as the difference between the growth rates of output and labour input. Let $y_{k t}$ and $L_{k t}$ be the output and labour input of a reference region $k$ at period $t$, where the output and labour input are the geometric means of all regions (Caves et al. 1982). Then by using Eq. (1), the labour productivity growth of the reference region $k$ at period $t$ is given by $\ell_{k t}$. We define the resilience of a region $i, \ell_{i}$, as the difference in the growth rate of labour productivity between the regions $i$ and $k$ as follows:

$$
\ell_{i}=\ell_{\mathrm{it}}-\ell_{\mathrm{kt}}=\ln \frac{\frac{y_{\mathrm{it}}}{L_{\mathrm{it}}}}{\frac{y_{\mathrm{it}-s}}{L_{\mathrm{it}-s}}}-\ln \frac{\frac{y_{\mathrm{kt}}}{L_{\mathrm{kt}}}}{\frac{y_{\mathrm{kt}-s}}{L_{\mathrm{kt}-s}}}
$$

Equation (2) can be equivalently interpreted as the growth rate of the difference in labour productivity of regions $i$ and $k$ between periods $t$ and $t-s$. 
Following Giannakis et al. (2021), who developed a production function framework to measure regional economic resilience in terms of output growth, and assuming that the production function is given by a first-order logarithmic Taylor series approximation (Cobb-Douglas), ${ }^{1}$ we have:

$$
\ln y_{\mathrm{it}}=-\ln \xi_{\mathrm{it}}+\ln \mathrm{A}_{\mathrm{it}}+\alpha \ln \mathrm{L}_{\mathrm{it}}+\beta \ln \mathrm{K}_{\mathrm{it}}
$$

where $y, L, K$ are the output, labour and capital inputs, respectively; $A_{i t}$ is the exogenous technical change (Total Factor Productivity); $\xi_{i t}$ measures the reduction of output due to the negative shock, when $\xi_{\text {it }}>1$; when $\xi_{\text {it }}=1$, the regional economy $i$ has economically fully recovered at time $t$.

Assuming constant returns to scale $(\alpha+\beta=1)$, labour productivity from Eq. (3) is given as:

$$
\ln \frac{y_{\mathrm{it}}}{L_{\mathrm{it}}}=-\ln \xi_{\mathrm{it}}+\ln A_{\mathrm{it}}+\beta \ln \frac{K_{\mathrm{it}}}{L_{\mathrm{it}}}
$$

The Eq. (4), from Eq. (1) can be expressed in terms of labour productivity growth between periods $t$ and $t-s$ as follows:

$$
\ell_{\mathrm{it}}=-\ln \frac{\xi_{\mathrm{it}}}{\xi_{\mathrm{it}-s}}+\ln \frac{A_{\mathrm{it}}}{A_{\mathrm{it}-s}}+\beta\left(\ln \frac{K_{\mathrm{it}}}{K_{\mathrm{it}-s}}-\ln \frac{L_{\mathrm{it}}}{L_{\mathrm{it}-s}}\right)
$$

Equation (5) shows that the labour productivity growth between $t$ and $t-s$ depends on the rate of change of the exogenous shock, the growth rate of the exogenous technical change, and the capital deepening, that is, the growth rate of capital minus the growth rate of labour. Similarly, the labour productivity of the average region $k$ between periods $t$ and $t-s$ can be defined as follows:

$$
\ell_{\mathrm{kt}}=-\ln \frac{\xi_{\mathrm{kt}}}{\xi_{\mathrm{kt}-s}}+\ln \frac{A_{\mathrm{kt}}}{A_{\mathrm{kt}-s}}+\beta\left(\ln \frac{K_{\mathrm{kt}}}{K_{\mathrm{kt}-s}}-\ln \frac{L_{\mathrm{kt}}}{L_{\mathrm{kt}-s}}\right)
$$

Then Eq. (2) from Eqs. (5) and (6) becomes:

$$
\begin{aligned}
\ell_{\imath}= & \left(\ln \frac{\xi_{\mathrm{it}-s}}{\xi_{\mathrm{kt}-s}}-\ln \frac{\xi_{\mathrm{it}}}{\xi_{\mathrm{kt}}}\right)+\left(\ln \frac{A_{\mathrm{it}}}{A_{\mathrm{it}-s}}-\ln \frac{A_{\mathrm{kt}}}{A_{\mathrm{kt}-s}}\right) \\
& +\beta\left[\left(\ln \frac{K_{\mathrm{it}}}{K_{\mathrm{it}-s}}-\ln \frac{L_{\mathrm{it}}}{L_{\mathrm{it}-s}}\right)-\left(\ln \frac{K_{\mathrm{kt}}}{K_{\mathrm{kt}-s}}-\ln \frac{L_{\mathrm{kt}}}{L_{\mathrm{kt}-s}}\right)\right]
\end{aligned}
$$

Equation (7) is not empirically identifiable since the level of exogenous technology and the effect of the negative shock are unknown.

To account for exogenous technical change, we assume that each region has an exponential growth of technology:

\footnotetext{
${ }^{1}$ Our framework can be defined for any general production function. For simplicity, we use here the Cobb-Douglas function.
} 


$$
A_{\mathrm{jt}}=A_{j 0} e^{\gamma_{j} t},(j=i, k)
$$

where $A_{j t}$ is the technology level of region $j$ at time $t, A_{j 0}$ is the initial level of technology, $\gamma_{j}$ is the exogenous technological rate; when $\gamma_{j}>0\left(\gamma_{j}<0\right)$ there is technical progress (recess).

The negative shock function $\left(\xi_{j t}\right)$ of region $j$, which depends on the common to each region shock and a vector of region-specific factors, can be formulated as follows:

$$
\xi_{\mathrm{jt}}=\xi_{0}(t) e^{\mathrm{bz}} \mathrm{z}_{\mathrm{jt}},(j=i, k)
$$

where $\xi_{0}(t)$ is the common exogenous shock to each region and it is a function of time; $z_{j t}$ is a set of regional characteristics at time $t$. If $b<0$, the characteristics $z_{j}$ observed in region $j$ will reduce the baseline negative effect of the shock $\left(\xi_{0}(t)\right)$ and therefore they will have a positive effect on the recovery of the regional economy.

Assuming that at time $t$ there is a full recovery of the economy, $\xi_{j t}=1$; substituting in Eq. (7), the Eqs. (8) and (9), we have:

$$
\ell_{i}=\left(\gamma_{i}-\gamma_{k}\right) \cdot s+b\left(z_{\mathrm{it}-s}-z_{\mathrm{kt}-s}\right)+\beta\left(x_{i}-x_{k}\right)
$$

where $x_{j}=\left(\ln \frac{K_{\mathrm{jt}}}{K_{\mathrm{jt}-s}}-\ln \frac{L_{\mathrm{jt}}}{L_{\mathrm{jt}-s}}\right)(j=i, k)$ is the capital deepening of region $j$.

Equation (10) shows that the difference in the labour productivity growth $\left(\ell_{i}\right)$ between region $i$ and a reference region $k$, i.e., our metric to operationalize the resilience of regional labour markets, depends on the difference in the growth rate of the exogenous technical change, the difference on the levels of the region-specific factors and the difference in the growth rate of the capital-labour ratio (capital deepening) between the two regions.

The main channels affecting the resilience of regional labour markets include changes in capital-labour ratio, either through capital accumulation or changes in the quantity and quality of the labour force; and second, shifts of the production function, either through changes in technology or negative shock. All other factors held equal, investment in capital that favours capital-labour substitution and technological progress increases the resilience of regional labour markets. On the contrary, negative shock reduces labour productivity growth due to a reduction in output. However, higher levels of pre-crisis region-specific factors like industrial interconnectedness, industrial concentration, agglomeration economies, and human capital, mitigate the negative shock and therefore accelerate the recovery of regional labour markets.

\section{Methods and data}

\subsection{Empirical model}

The empirical model of the paper is based on Eq. (10). However, considering that the resilience of regional labour markets might depend not only on their own 
characteristics but also on features of neighbouring regions (Pontarollo and Serpieri 2020a; Ezcurra and Rios 2019; Cainelli et al. 2019b), we apply spatial regression models to explore the effect of spatial spillovers on regional labour markets resilience. Two of the most popular spatial regression specifications to account for the effect of spatial spillovers are: (a) global spillover models that include a spatial lag of the dependent variable and (b) local spillover models including spatial lags of the explanatory variables (LeSage 2015). LeSage (2014a) argues that there are two main spatial model specifications that need to be considered when there is uncertainty about the optimal model to use, namely, the spatial Durbin global spillover model (SDM) and the spatial Durbin error local spillover model (SDEM). The spatially lagged X model (SLX) is another local spillover specification, which is nested to both SDM and SDEM. Following this line of reasoning, similar to Cainelli et al. (2019b), we apply the SDM, SDEM and SLX cross-sectional models to estimate Eq. (10).

The SDM, which captures global spatial spillovers through spatial lag terms of both the dependent variable and the explanatory variables, takes the form (LeSage 2014b):

$$
\ell_{i}=a_{i}+Z_{i} b+\beta X_{i}+W \Phi_{i} \pi+\rho W \ell_{i}+\varepsilon_{i}
$$

where $a_{i}=\left(\gamma_{i}-\gamma_{k}\right) \cdot s$ is the constant term that captures the difference in the productivity growth between region $i$ and region $k ; Z_{i}=\left(z_{i}-z_{k}\right)$ is a $n \times m$ matrix of the difference in the region-specific factors between region $i$ and the average of all regions (identified with index $k$ ); $X_{i}=\left(x_{i}-x_{k}\right)$ is a $n \times 1$ vector of the difference in the capital deepening between region $i$ and region $k ; b$ is a $m x 1$ vector of coefficients that captures the effect of region-specific factors on regional resilience; $\beta$ captures the effect of capital deepening; $W$ is a $n \times n$ row-standardized spatial weights matrix used to model spillover effects across regions; $\Phi_{i}=\left(Z_{i}, X_{i}\right)$ is a $n \times(m+1)$ matrix of the region-specific factors and the capital deepening; $\pi$ is a $(m+1) \times 1$ vector of spatial parameters referring to the spatially lagged region-specific factors and the spatially lagged capital deepening; $\rho$ is the spatial autoregressive parameter; $W \ell_{i}$ is a $n x 1$ vector of the spatially lagged dependent variable $\ell$; $\varepsilon_{i}$ is a $n \times 1$ vector of error terms.

The SDEM captures local spillovers to immediate neighbouring regions but also allows for global diffusion of shocks to the model disturbances, i.e., the effect of a change in the disturbance of a given region on disturbances of neighbouring regions (LeSage 2014b). The SDEM takes the form:

$$
\ell_{i}=a_{i}+Z_{i} b+\beta X_{i}+W \Phi_{i} \pi+\mu_{i}
$$

with $\mu_{i}=\lambda W \mu_{i}+\varepsilon_{i}$, where $\lambda$ is the spatial error parameter.

The SLX model, which captures local spatial spillovers to neighbouring regions through spatial lag terms for the explanatory variables, takes the form (LeSage 2014b):

$$
\ell_{i}=a_{i}+Z_{i} b+\beta X_{i}+W \Phi_{i} \pi+\varepsilon_{i}
$$


We apply a Bayesian model selection approach to choose between the three models (LeSage 2014a). The model selection procedure is based on the comparison of the log-marginal likelihood values of the different models using alternative row-standardised spatial weight matrices. The MATLAB algorithms developed by LeSage (2015) were used to calculate spatial weight matrices and log-marginal likelihood values. Details about the theoretical foundation of the applied Bayesian approach can be found in LeSage (2014a).

\subsection{Measuring regional labour markets resilience}

We empirically measure the resilience of regional labour markets $\left(\ell_{i}\right)$ across the EU-28 NUTS-2 regions, based on Eqs. (1) and (2), as follows:

$$
\ell_{i}=\left(\ln \frac{\mathrm{GVA}_{i 2016}}{\mathrm{GVA}_{i 2008}}-\ln \frac{\mathrm{GVA}_{k 2016}}{\mathrm{GVA}_{k 2008}}\right)-\left(\ln \frac{L_{i 2016}}{L_{i 2008}}-\ln \frac{L_{k 2016}}{L_{k 2008}}\right)
$$

where $i$ identifies the NUTS-2 regional labour markets, $i=1,276 ; k$ is a reference regional labour market which represents the geometric mean of all regional labour markets; $G V A_{i}$ is the gross value added in region $i$ in 2008, that is, the starting year of the crisis period and 2016, that is, the end year of the economic period at constant 2010 prices (euro); $L_{i}$ is the compensation of employment (employees and selfemployed persons expressed in hours of work) at constant 2010 prices (euro).

The compensation of employment is the sum of the compensation of employees (Eurostat 2020a, 2021) and the compensation of the self-employed. Eurostat is the source for the annual regional GVA data (Eurostat 2020a). Eurostat is also the source for the regional compensation of employees data (Eurostat 2020b) and the regional employment data per professional status (Eurostat 2020c).

The spatial distribution of regional labour markets resilience, which is portrayed in Fig. 1, highlights the uneven ability of regional labour markets to withstand, react and recover from the economic shock. The geography of the regional labour markets resilience is clearly influenced by national patterns. Clusters of low resilient labour markets are observed in countries such as Italy and Greece as a result of the relatively higher employment growth rates compared to the output growth rates. For example, although it is well known that the northern regions in Italy are more developed than the southern regions (Lagravinese 2015), the growth rate of the labour productivity in almost all Italian regions is lower than the labour productivity growth rate of the reference region. On the contrary, high-resilient labour markets surrounded by high-resilient labour markets are present in countries such as Spain, Romania and Bulgaria. A heterogeneous pattern of resilience can also be observed within countries. This is particularly evident in countries such as Germany, France, Netherlands, and UK. 


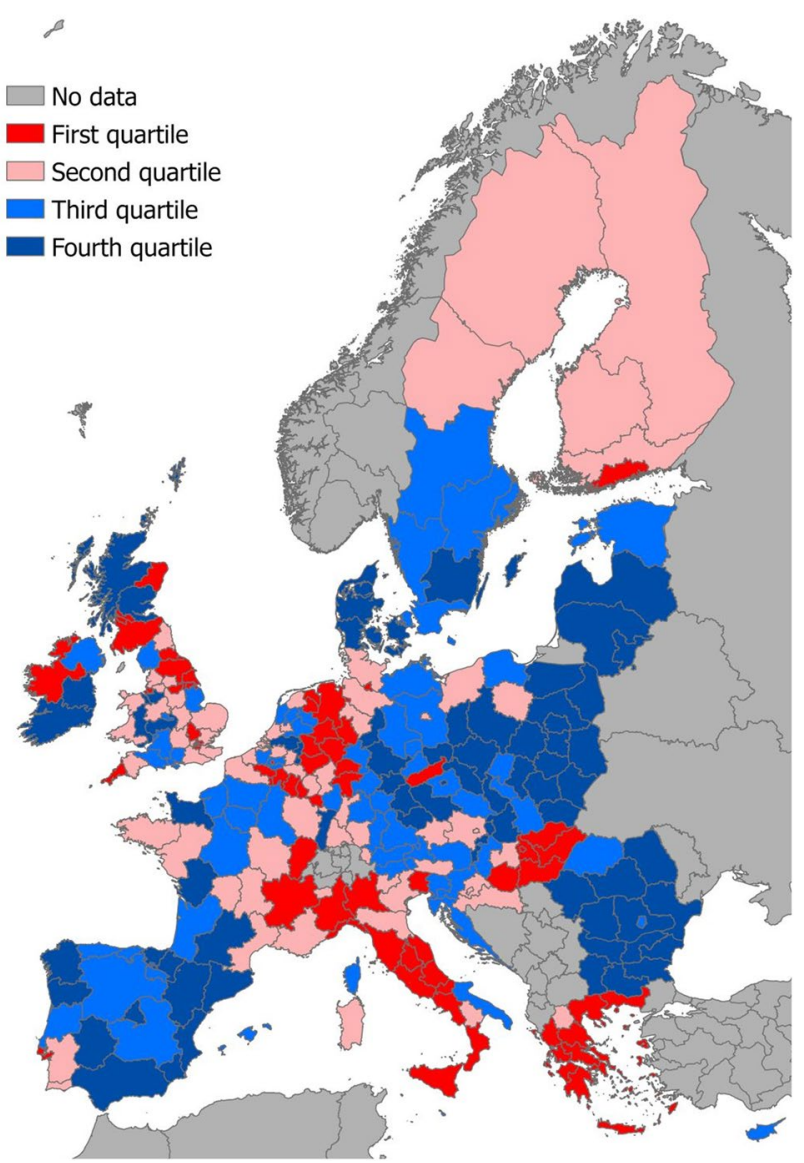

Fig. 1 Regional labour markets resilience across EU-28 NUTS-2 regions for the 2008-2016 period

\subsection{Capital deepening}

The capital deepening $\left(x_{i}\right)$ equals the growth rate of capital minus the growth rate of labour between 2008 and 2016. The perpetual inventory method was applied to construct capital stock series for each region (see Appendix A). The regional gross fixed capital formation data (Eurostat 2020d) were used to construct the regional capital stock series for the period 2000-2017.

\subsection{Region-specific factors}

The pre-crisis region-specific factors $\left(z_{i}\right)$ included in the empirical model for the year 2007 are: (1) industrial interconnectedness, (2) industrial concentration, (3) agglomeration economies, and (4) human capital factors. 


\subsubsection{Industrial interconnectedness}

We applied the IO modelling framework to empirically measure the interdependences between economic sectors via backward and forward linkages. The backward linkages of a certain sector $j\left(B L_{j}\right)$ measure the effects of a change in the final demand of the sector $j$ on the output of all sectors. Backward linkages are given by the column sums of the Leontief-inverse matrix based on the technical input coefficients that relate the intermediate inputs of a sector to the sector's total inputs (Rasmussen 1956). The forward linkages of a certain sector $i\left(F L_{i}\right)$ measure the effects of a change in the primary inputs of the sector $i$ on the output of all sectors. Forward linkages are given by the row sums of the output-inverse matrix based on the technical output coefficients that relate the intermediate sales of a sector to the sector's total sales (Jones 1976).

The national symmetric IO tables for the 28 EU countries for the year 2007, which were derived from the WIOD database (Timmer et al. 2015), were used to construct 276 regional IO models for the EU-28 NUTS-2 regions. The initial 56-sector classification of the EU-28 national IO tables was aggregated to 8-sector regional schemes including (a) Agriculture, (b) Manufacturing, (c) Construction, (d) Trade, Transport, Accommodation, (e) Finance, (f) Real Estate, (g) Public Administration, Health, Education, (h) Others (Table B1). The methodology for the construction of the regional IO tables is described in Appendix B.

\subsubsection{Industrial concentration}

A Herfindahl-Hirschman index $\left(\right.$ Hindex $\left._{i t}\right)$ was constructed, using GVA data, to measure the industrial concentration across regions as follows:

$$
\text { Hindex }_{i t}=\sum_{j=1}^{n} S_{\mathrm{ijt}}^{2}
$$

where $S_{i j t}^{2}$ is the gross value added share in region $i$ in sector $j$ in year $t(t=2007)$ (Eurostat 2020a). The higher the value of the Hindex $_{i t}$, the higher the sectoral concentration of the regional labour market in question.

\subsubsection{Agglomeration economies}

A measure of employment density (thousand persons per square kilometre) was used to capture the effect of agglomeration forces in regional resilience (Eurostat 2020e; 2020f). 
Table 1 Data descriptive statistics for the 276 EU-28 NUTS-2 regions

\begin{tabular}{|c|c|c|c|c|}
\hline & Mean & Std. Dev & Min & Max \\
\hline Labour productivity growth & 0.047 & 0.095 & -0.346 & 0.415 \\
\hline BL Agriculture & 1.580 & 0.161 & 1.000 & 1.855 \\
\hline BL Manufacturing & 1.673 & 0.162 & 1.230 & 2.027 \\
\hline BL Construction & 1.793 & 0.204 & 1.332 & 2.289 \\
\hline BL Trade, Transportation, Accommodation & 1.593 & 0.091 & 1.302 & 1.768 \\
\hline BL Finance & 1.664 & 0.191 & 1.225 & 2.085 \\
\hline BL Real Estate & 1.318 & 0.133 & 1.000 & 1.674 \\
\hline BL Public Administration, Health, Education & 1.331 & 0.072 & 1.106 & 1.489 \\
\hline FL Agriculture & 1.751 & 0.236 & 1.192 & 2.379 \\
\hline FL Manufacturing & 1.502 & 0.175 & 1.200 & 1.992 \\
\hline FL Construction & 1.494 & 0.182 & 1.132 & 1.913 \\
\hline FL Trade, Transportation, Accommodation & 1.676 & 0.148 & 1.255 & 2.010 \\
\hline FL Finance & 1.945 & 0.216 & 1.253 & 2.521 \\
\hline FL Real Estate & 1.427 & 0.162 & 1.000 & 1.761 \\
\hline FL Public Administration, Health, Education & 1.114 & 0.048 & 1.034 & 1.206 \\
\hline Hindex & 0.234 & 0.029 & 0.188 & 0.389 \\
\hline Employment Density & 0.191 & 0.493 & 0.001 & 4.866 \\
\hline Secondary Education & 0.473 & 0.153 & 0.107 & 0.796 \\
\hline Tertiary Education & 0.234 & 0.089 & 0.073 & 0.608 \\
\hline Age3049 & 0.291 & 0.019 & 0.248 & 0.353 \\
\hline Age5064 & 0.185 & 0.019 & 0.097 & 0.239 \\
\hline Age $65+$ & 0.170 & 0.033 & 0.038 & 0.270 \\
\hline Capital deepening & 0.264 & 0.139 & -0.028 & 0.871 \\
\hline
\end{tabular}

$B L$ Backward Linkages; FL Forward Linkages

\subsubsection{Human capital}

The share of population with secondary or tertiary education was used to capture the educational effects in regional labour markets resilience (Eurostat 2020g). Several age cohorts were introduced in the analysis to capture the effect of age structure, that is, share of population aged 30-49, share of population aged 50-64, and share of population older than 65 years (Eurostat 2020h).

Table 1 presents the descriptive statistics of the data used in the empirical analysis. A correlation matrix of the explanatory variables is presented in Appendix C (Table C1)

\section{Results and discussion}

Table 2 reports the log-marginal likelihood values and the posterior model probabilities calculated for the SLX model, the SDM and the SDEM with respect to a broad range of alternative spatial weight matrices, including matrices based on the 
Table 2 Spatial Bayesian model selection: log-marginal likelihood (LML) values and posterior model probabilities $(p)$

\begin{tabular}{|c|c|c|c|c|c|c|}
\hline \multirow[t]{2}{*}{ Spatial weights matrix $(\boldsymbol{W})$} & \multicolumn{2}{|l|}{ SLX } & \multicolumn{2}{|l|}{ SDM } & \multicolumn{2}{|l|}{ SDEM } \\
\hline & LML & $p$ & LML & $p$ & LML & $p$ \\
\hline 8-nearest neighbours & 331.759 & 0.000 & 331.619 & 0.000 & 335.640 & 0.000 \\
\hline 9-nearest neighbours & 333.555 & 0.000 & 333.376 & 0.000 & 338.215 & 0.006 \\
\hline 10-nearest neighbours & 336.622 & 0.001 & 336.306 & 0.001 & 339.000 & 0.013 \\
\hline 11-nearest neighbours & 336.872 & 0.002 & 336.668 & 0.001 & 340.520 & 0.058 \\
\hline 12-nearest neighbours & 335.582 & 0.000 & 335.432 & 0.000 & 339.247 & 0.016 \\
\hline 13-nearest neighbours & 338.091 & 0.005 & 337.929 & 0.004 & 342.551 & 0.442 \\
\hline 14-nearest neighbours & 338.766 & 0.010 & 338.909 & 0.012 & 342.164 & 0.301 \\
\hline 15-nearest neighbours & 338.660 & 0.009 & 339.053 & 0.013 & 340.510 & 0.058 \\
\hline 16-nearest neighbours & 337.803 & 0.004 & 337.847 & 0.004 & 340.071 & 0.037 \\
\hline Contiguity & 328.508 & 0.000 & 328.413 & 0.000 & 328.101 & 0.000 \\
\hline $1 / d^{2}$, cut-off at $\mathrm{Q} 1$ & 330.132 & 0.000 & 330.521 & 0.000 & 329.998 & 0.000 \\
\hline $1 / d^{2}$, cut-off at Q2 & 335.337 & 0.000 & 335.599 & 0.000 & 335.711 & 0.001 \\
\hline $1 / d^{2}$, cut-off at Q3 & 335.337 & 0.000 & 335.599 & 0.000 & 335.711 & 0.001 \\
\hline$e^{-0.02 d}$, cut-off at Q1 & 323.371 & 0.000 & 322.895 & 0.000 & 323.030 & 0.000 \\
\hline$e^{-0.02 d}$, cut-off at Q2 & 326.428 & 0.000 & 325.954 & 0.000 & 326.032 & 0.000 \\
\hline$e^{-0.02 d}$, cut-off at Q3 & 326.428 & 0.000 & 325.954 & 0.000 & 326.032 & 0.000 \\
\hline$e^{-0.05 d}$, cut-off at Q1 & 316.414 & 0.000 & 316.246 & 0.000 & 316.209 & 0.000 \\
\hline$e^{-0.05 d}$, cut-off at Q2 & 318.546 & 0.000 & 318.433 & 0.000 & 318.285 & 0.000 \\
\hline$e^{-0.05 d}$, cut-off at Q3 & 318.546 & 0.000 & 318.433 & 0.000 & 318.285 & 0.000 \\
\hline
\end{tabular}

Q1, Q2 and Q3 are, respectively, the first, second and third quartiles of the distribution of distances; $d$ is the distance between the centroids of the regions

$k$-nearest neighbours, the inverse of the squared distance, and the exponential decay function with different cut-offs. All matrices are row-standardized. The results of the Bayesian model selection procedure suggest that the SDEM is the preferred spatial specification. Specifically, a 13 nearest neighbours spatial weight matrix is associated with the 'best' SDEM specification (posterior model probability, $p=0.442$ ).

Table 3 reports the results of the maximum likelihood estimation of the SDEM associated with a 13 nearest neighbours spatial weight matrix. In addition to the Bayesian model selection procedure, standard Wald tests, which are reported in Table 3, confirm the validity of the SDEM specification. The hypothesis that the spatially lagged explanatory variables and the spatial lag of the error term are jointly equal to zero $(\lambda=\pi=0)$ is decisively rejected. Similarly, the hypotheses that $\lambda=0$ (SLX) and $\pi=0$ (Spatial Error Model) are also rejected (Table 3). The spatial error parameter $(\lambda)$ is negative and statistically significant indicating the diffusion of global shocks, through changes in disturbances, in regional labour markets. 
Table 3 Regression estimates of the pre-crisis (2007) determinants of regional labour markets resilience for the Spatial Durbin Error Model (SDEM) for the 276 EU-28 NUTS-2 regions

\begin{tabular}{|c|c|c|c|c|}
\hline & \multicolumn{2}{|l|}{ Direct effects } & \multicolumn{2}{|c|}{ Indirect effects $(W \times \Phi)$} \\
\hline & Coef & Robust Std. Err & Coef & Robust Std. Err \\
\hline BL Agriculture & -0.022 & 0.050 & 0.165 & 0.187 \\
\hline BL Manufacturing & 0.037 & 0.162 & 0.132 & 0.395 \\
\hline BL Construction & $-0.291^{*}$ & 0.115 & -0.547 & 0.345 \\
\hline $\begin{array}{l}\text { BL Trade, Transportation, Accommoda- } \\
\text { tion }\end{array}$ & -0.131 & 0.246 & $0.946^{*}$ & 0.431 \\
\hline BL Finance & -0.315 & 0.190 & -0.208 & 0.175 \\
\hline BL Real Estate & -0.044 & 0.153 & $0.560^{*}$ & 0.261 \\
\hline $\begin{array}{l}\text { BL Public Administration, Health, Educa- } \\
\text { tion }\end{array}$ & 0.409 & 0.303 & -0.162 & 0.341 \\
\hline FL Agriculture & 0.013 & 0.045 & 0.140 & 0.158 \\
\hline FL Manufacturing & -0.271 & 0.262 & -0.035 & 0.458 \\
\hline FL Construction & $0.427^{*}$ & 0.189 & $0.659^{*}$ & 0.271 \\
\hline $\begin{array}{l}\text { FL Trade, Transportation, Accommoda- } \\
\text { tion }\end{array}$ & 0.177 & 0.160 & -0.148 & 0.209 \\
\hline FL Finance & 0.054 & 0.065 & 0.031 & 0.142 \\
\hline FL Real Estate & 0.097 & 0.121 & -0.123 & 0.218 \\
\hline $\begin{array}{l}\text { FL Public Administration, Health, Educa- } \\
\text { tion }\end{array}$ & -0.160 & 1.024 & $-2.260^{* *}$ & 0.736 \\
\hline Hindex & $-0.983^{* *}$ & 0.222 & -1.625 & 0.992 \\
\hline Employment Density & -0.009 & 0.013 & -0.030 & 0.041 \\
\hline Secondary Education & 0.032 & 0.109 & -0.048 & 0.201 \\
\hline Tertiary Education & 0.174 & 0.096 & $0.508^{*}$ & 0.232 \\
\hline Age3049 & -0.637 & 0.474 & -2.179 & 1.162 \\
\hline Age5064 & -0.542 & 0.472 & $-3.517^{* *}$ & 1.279 \\
\hline Age65 + & -0.166 & 0.299 & 0.942 & 0.732 \\
\hline Capital Deepening & $0.293^{* *}$ & 0.037 & -0.213 & 0.164 \\
\hline Constant & -0.065 & 0.070 & & \\
\hline Spatial error parameter $\lambda$ & $-0.761^{* *}$ & 0.216 & & \\
\hline Country dummies & Yes & & & \\
\hline Pseudo R-squared & 0.731 & & & \\
\hline Log-likelihood & 445.44 & & & \\
\hline Hypotheses & Wald tests & & & \\
\hline$\lambda=\pi=0$ & $\chi_{23}^{2}=82.40^{* *}$ & & & \\
\hline$\lambda=0$ & $\chi_{1}^{2}=12.40^{* * *}$ & & & \\
\hline$\pi=0$ & $\chi_{22}^{2}=69.96^{* * *}$ & & & \\
\hline Country dummies $=0$ & $\chi_{27}^{2}=60.66^{* *}$ & & & \\
\hline
\end{tabular}

${ }^{*} p<0.05 ;{ }^{* *} p<0.01$

$B L$ Backward Linkages; FL Forward Linkages 
First, we consider the effects of region-specific factors that reduce the baseline negative effect of economic shock. Note that a negative sign of the coefficient $b$ reduces the negative effect of the shock and thus it positively influences the recovery of regional labour markets. Our empirical results indicate that intersectoral linkages create a diverse effect on regional labour markets resilience. The backward linkages of the Construction sector are positively associated with the resilience of labour markets, i.e., the higher the pre-crisis supplies linkages of the Construction sector in the local economy the higher the resilience of the labour market to economic shocks. On the contrary, the forward linkages of the Construction sector are negatively associated with the resilience of the labour markets, i.e., the higher the pre-crisis sales linkages of the Construction sector in the local economy the weaker the resilience of the labour markets to economic shocks. The effect of backward and forward linkages of the remaining economic sectors, either positive or negative, is not statistically significant. ${ }^{2}$

Grabner et al (2020) explored the role of regional economic embeddedness on the resilience of the EU NUTS-2 labour markets during 2000-2010. The findings of the study, in line with our results, indicate that regions with high supplies (backward) embeddedness of the Construction sector were more resilient to economic shocks. On the contrary, regions with strong sales (forward) embeddedness of the Construction sector were less resilient to economic disruptions. Similar results about the importance of the Construction sector's embeddedness in the resilience of the UK NUTS-2 regions are reported by Kitsos et al. (2019). Klimek et al. (2019) using input-output models showed that the Construction sector in the USA had the fastest rebound from economic shocks during the period 2000-2014. Giannakis and Bruggeman (2017a) found that backward linkages of the Construction sector in Greek NUTS-2 regions increased by $16 \%$ between 2004 and 2011.

The Construction sector generally exhibits a higher economic pull (backward) than push (forward) effect. This is due to the nature of the construction operations that need many different inputs from a large number of economic sectors and due to the nature of the demand for the construction outputs that are considered derived demand from other economic activities (Pietroforte and Gregori 2003; Liu and He 2016). Specifically, the Construction sector cannot itself create demand for its output, thus if other sectors cannot absorb the construction outputs or the sector expands beyond the adaptive capacity of the economy, it negatively impacts the economy (Pietroforte and Gregori 2003; Song and Liu 2006).

Our findings indicate that the pre-crisis industrial concentration (Hindex) has a positive effect on the ability of regional labour markets to withstand and recover from exogenous shocks. Giannakis and Bruggeman (2017b) showed that European regional economies with more specialized labour markets (i.e., high

\footnotetext{
${ }^{2}$ We re-estimated the model by dropping the explanatory variables with correlation coefficients greater than 0.60 (Table C1) and the results remained the same. In addition, we estimated the effect of the aggregated industrial interconnectedness (weighted by the output sectoral shares) on regional labour markets resilience. The estimated parameter for the aggregated interconnectedness was not statistically significant but the rest of the parameters remained similar.
} 
Herfindahl-Hirschman index) relative to EU-28 were more likely to withstand the impact of the 2008 economic crisis compared to regions with more diversified labour markets. Van Oort et al. (2015) found a positive relationship between specialization and productivity growth across EU NUTS-2 regions between 2000 and 2010, particularly for large urban and capital regions. On the contrary, Cainelli et al. (2019a) found that industrial concentration had a negative effect across the EU during the 2008-2012 crisis period. Similarly, Holl (2018) and Di Caro (2017), in their studies of regional resilience in Spain and Italy, respectively, emphasize greater resilience in regions with a large diversity of employment.

The effect of agglomeration forces, here proxied by employment density, is positive for the resilience of regional labour markets, but this relationship is not statistically significant. Similarly, the effect of human capital variables, i.e., education and age structure, is not statistically significant.

Next, our estimates show, as it was expected, that the coefficient of capital deepening is statistically significant and close to the capital revenue share observed in the data. Several authors have stressed the importance of capital deepening in labour productivity growth (Filippetti and Peyrache 2015; Christopoulos and Tsionas 2004). Since we consider only two periods in our analysis, we cannot estimate exogenous technical change differences across regions. However, we introduce country dummies to capture exogenous technical change differences across countries. Country dummies are jointly significant at $1 \%$ and therefore we can reject the null hypothesis that the coefficients of the dummy variables are zero (Table 3).

The statistically significant spatial lags of several independent variables in the second part of Table 3 show the spatial spillover effects of changes in neighbouring regions on own-region labour market resilience. Specifically, the statistically significant coefficients of the spatially lagged backward linkages of the Trade, Transportation, Accommodation and Real Estate sectors indicate that high linkages of those sectors in neighbouring regional labour markets reduce the own-region labour market resilience. Similarly, the indirect effect associated with the forward linkages of the Construction sector is negative revealing negative spillovers from neighbouring labour markets on own-labour market resilience. On the contrary, high forward linkages of the Public Administration, Health and Education sector in neighbouring labour markets increase own-labour market resilience. Interestingly, the indirect effect associated with the share of population with tertiary education is negative indicating negative spillover effects arising from the neighbouring regional markets due to the effects of competition between labour markets. Finally, a high share of the population aged between 50 and 64 in neighbouring labour markets increases ownlabour market resilience.

\section{Conclusions}

This paper conceptualizes and empirically measures the resilience of EU regional labour markets in terms of labour productivity growth. Our analysis assesses the effect of pre-crisis region-specific factors on the resilience of spatial labour markets 
controlling for the effect of exogenous technological change and substitution of labour with capital across European regions.

The empirical analysis of the paper reveals a positive association between the pre-crisis economic pull capabilities of the Construction sector and the resilience of regional labour markets, which derives from the reduction of baseline negative shock. As such, the Construction sector can play an important role in the recovery of EU regions and it should be a key priority of the current (e.g., the Next Generation EU instrument for economic recovery from the coronavirus pandemic) and future stimulus packages for overcoming the adverse effects of negative shocks. However, the negative association of the push capabilities of the sector with the resilience of labour markets indicate that the Construction sector can positively affect the recovery of labour markets when there is sufficient demand from other sectors to absorb the outputs of the sector. An over-expansion of construction operations may generate inflationary pressures and thus negatively affect the stability of regional economies.

Our findings indicate that pre-crisis industrial concentration has a positive effect on regional labour markets resilience, which derives again from the reduction of baseline negative shock. Place-based policies building on regions' competitive strengths can smooth out the negative effect of exogenous shock, and thus allow a faster recovery of regional economies. Finally, our study confirms the importance of capital deepening in labour productivity growth. As such, policy interventions promoting capital investment in digital transformation, research and development, competitiveness, and innovation included in the current EU Recovery and Resilience Plan, can further enhance labour productivity in EU regions.

\section{Appendix A: Construction of capital stock series for EU-28 NUTS-2 regions}

The perpetual inventory method was used to construct capital stock series for each EU-28 NUTS-2 region $i$ as follows (OECD 2009):

$$
K_{t}=K_{t-1}+I_{t-1}-D_{t-1}
$$

where $K_{t}$ is the net capital stock at period $t ; K_{t-1}$ is the net capital stock at the previous period $t-1 ; I_{t-1}$ is the gross investment in the previous period $t-1 ; D_{t}$ is the depreciation in the current period $t$. Assuming that all regions have geometric depreciation rate, Equation (A.1) can be written as follows:

$$
K_{t}=(1-\delta) K_{t-1}+I_{t-1}
$$

The gross fixed capital formation data, available from Eurostat (2020d), are used as a proxy for investment $(I)$ to construct a capital stock series $(K)$ for the period 2000-2017. We further assume $\delta$ equals 0.07 (Levenko et al. 2019). The initial capital stock $\left(\mathrm{K}_{2000}\right)$ is computed as follows (OECD 2009): 


$$
K_{2000}=\frac{I_{2000}}{g+\delta}
$$

where $g$ is the growth rate of investment which is proxied here by the average growth rate of gross domestic product for the period 1995-1999.

\section{Appendix B: Construction of regional input-output tables for EU-28 NUTS-2 regions}

In this study, we used non-survey techniques to construct regional IO tables. The non-survey techniques involve the representation of the structure of the regional economy through the modification of the national technical coefficients (Giannakis and Bruggeman 2017a).

The regional IO technical coefficients $a_{i j}^{R}$ can be estimated as follows (Tohmo 2004):

$$
a_{\mathrm{ij}}^{R}=t_{\mathrm{ij}}^{R} \cdot a_{\mathrm{ij}}^{N}
$$

where $a_{\mathrm{ij}}^{N}$ are the national IO coefficients $(N=1,28) ; t_{\mathrm{ij}}^{R}$ are the regional trading coefficients and $i$ and $j$ identify the sectors.

The regional trading coefficients $\left(t_{i j}^{R}\right)$ are typically estimated via the application of employment-based location quotients (LQ) (Flegg and Tohmo 2013). Here, we apply the cross industry location quotients (CILQ) formula as follows (Giannakis and Bruggeman 2017a):

$$
\mathrm{CILQ}_{\mathrm{ij}}^{R}=\left[\frac{E_{i}^{R} / E_{i}^{N}}{E_{j}^{R} / E_{j}^{N}}\right]
$$

where $E_{i}^{R}$ and $E_{j}^{R}$ are employment in sectors $i$ and $j$ in region $R ; E_{i}^{N}$ and $E_{j}^{N}$ are employment in sectors $i$ and $j$ in country $N$.

If $\mathrm{CILQ}_{\mathrm{ij}}^{R}<1$, it is assumed that some of the needs of sector $j$ for input from sector $i$ have to be imported from another region, and the national coefficients will be adjusted downwards by multiplying them by the $\mathrm{CILQ}_{\mathrm{ij}}^{R}$. If $\mathrm{CILQ}_{\mathrm{ij}}^{R} \geq 1$, it is assumed that all needs of sector $j$ for input from sector $i$ can be met within the region. Thus, the regional IO coefficients can be computed as follows:

$$
a_{\mathrm{ij}}^{R}=\left\{\begin{array}{l}
a_{\mathrm{ij}}^{N} \mathrm{CILQ}_{\mathrm{ij}}^{R} \text { if } \mathrm{CILQ}_{\mathrm{ij}}^{R}<1 \\
a_{\mathrm{ij}}^{N} \text { if } \mathrm{CILQ}_{\mathrm{ij}}^{R} \geq 1
\end{array}\right\}
$$


Table B1 presents the aggregated 8-sector classification of the 276 EU-28 NUTS-2 regional IO tables for the year 2007.

\section{See Table B1}

Table B1 NACE (Statistical classification of economic activities in the European Union) codes of the sectors of economic activity for the 276 EU-28 NUTS-2 regions

\begin{tabular}{lll}
\hline $\mathrm{n} / \mathrm{n}$ & Sector & NACE code \\
\hline 1 & Agriculture & A01-A03 \\
2 & Manufacturing & C10-C33 \\
3 & Construction & F \\
4 & Trade, Transport, Accommodation & G45-G47, H50-H53, I \\
5 & Finance & K64-K66 \\
6 & Real Estate & L68 \\
7 & Public administration, Health, Education & O84, P85, Q \\
8 & Others & B, D35, E36-E39, J58- \\
& & J63, M69-M75, N, R, \\
\end{tabular}

Source: Eurostat (2008)

\section{Appendix C: Correlation matrix}

See Table C1 


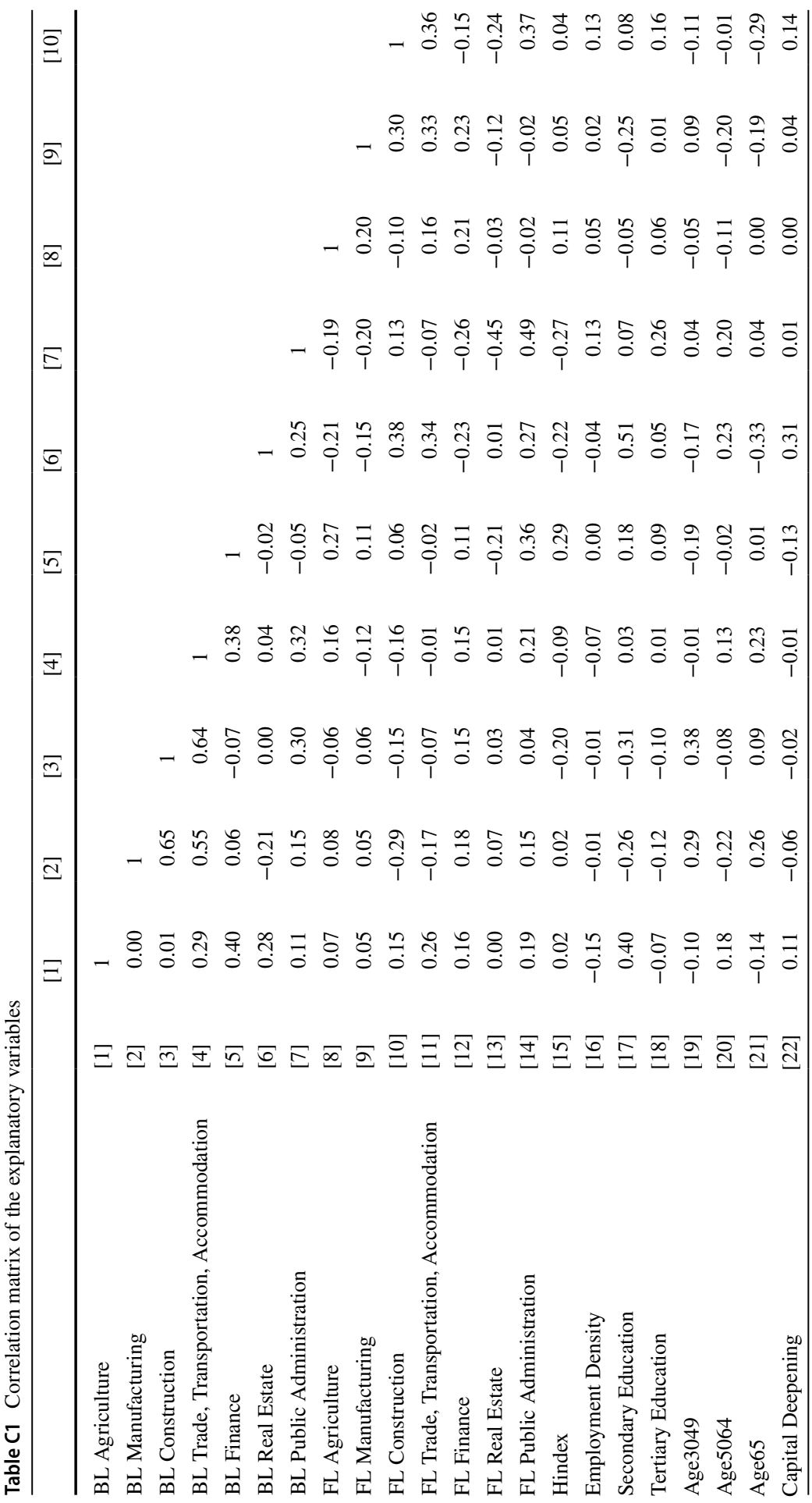




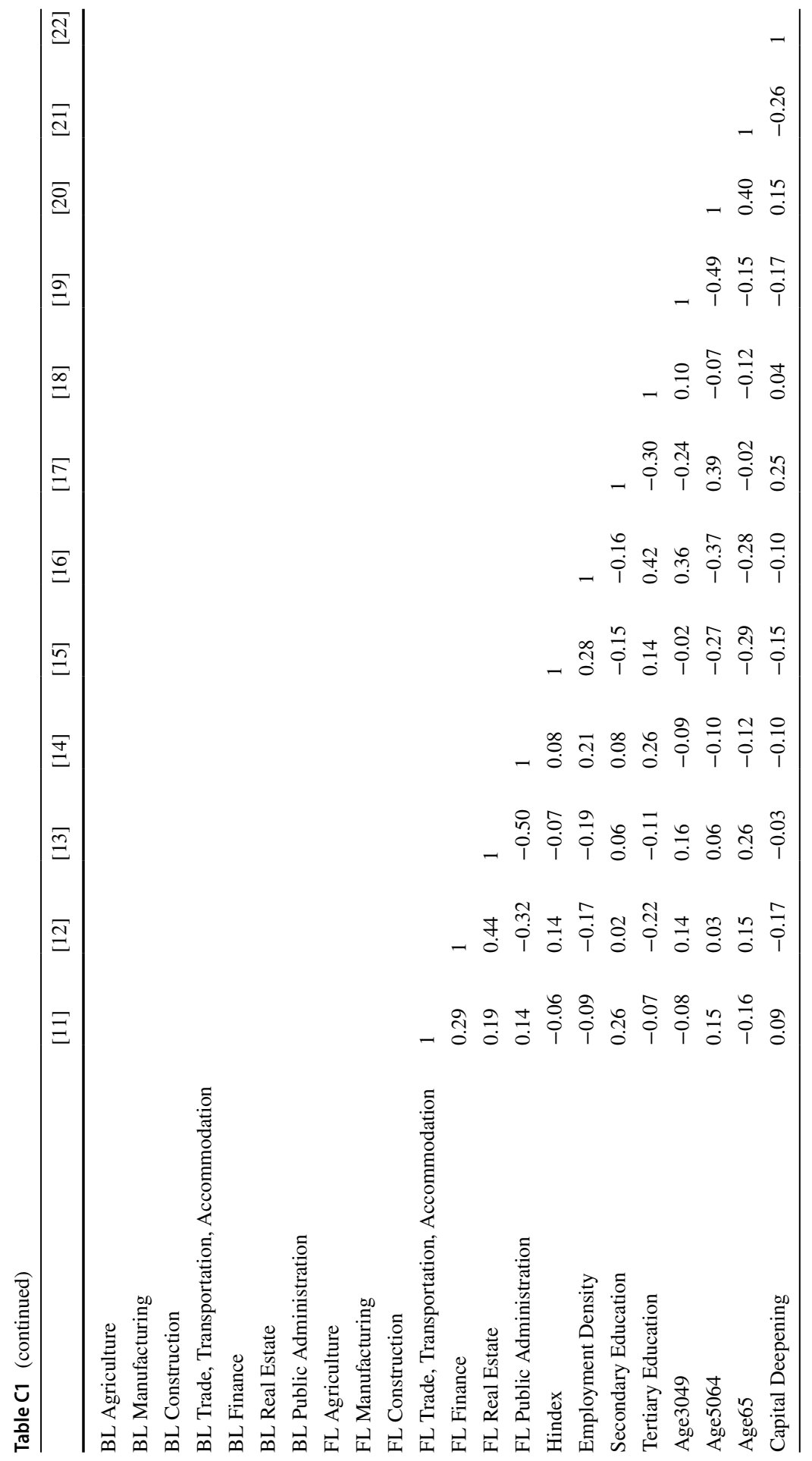


Acknowledgements The authors would like to thank the anonymous reviewer and the editor for their constructive comments and suggestions that greatly improved the final version of the paper.

\section{References}

Acemoglu D, Akcigit U, Kerr W (2016) Networks and the macroeconomy: an empirical exploration. NBER Macroecon Annu 30(1):273-335

Basile R, De Benedictis L (2008) Regional unemployment and productivity in Europe. Pap Reg Sci 87(2):173-192

Boschma R (2015) Towards an evolutionary perspective on regional resilience. Reg Stud 49(5):733-751

Cainelli G, Ganau R, Modica M (2019a) Industrial relatedness and regional resilience in the European Union. Pap Reg Sci 98(2):755-778

Cainelli G, Ganau R, Modica M (2019b) Does related variety affect regional resilience? New evidence from Italy. Ann Reg Sci 62(3):657-680

Caves DW, Christensen LR, Diewert WE (1982) Multilateral comparisons of output, input, and productivity using superlative index numbers. Econ J 92(365):73-86

Christopoulos DK, Tsionas EG (2004) Convergence and regional productivity differences: evidence from Greek prefectures. Ann Reg Sci 38(3):387-396

Crescenzi R, Luca D, Milio S (2016) The geography of the economic crisis in Europe: national macroeconomic conditions, regional structural factors and short-term economic performance. Camb J Reg Econ Soc 9(1):13-32

Cuadrado-Roura JR, Mancha-Navarro T, Garrido-Yserte R (2000) Regional productivity patterns in Europe: an alternative approach. Ann Reg Sci 34(3):365-384

Di Caro P (2017) Testing and explaining economic resilience with an application to Italian regions. Pap Reg Sci 96(1):93-113

Di Caro P, Fratesi U (2018) Regional determinants of economic resilience. Ann Reg Sci 60(2):235-240

Diodato D, Weterings AB (2015) The resilience of regional labour markets to economic shocks: Exploring the role of interactions among firms and workers. J Econ Geogr 15(4):723-742

Eurostat (2008) Statistical classification of economic activities in the European Community. NACE Rev. 2. Office for Official Publications of the European Communities, Luxembourg

Eurostat (2020a) Gross value added at basic prices by NUTS 3 regions [nama_10r_3gva]. Retrieved from https://ec.europa.eu/eurostat/web/products-datasets/product?code=nama_10r_3gva

Eurostat (2020b) GDP and main components (output, expenditure and income) [nama_10_gdp]. Retrieved from https://appsso.eurostat.ec.europa.eu/nui/show.do?dataset=nama_10_gdp\&lang=en

Eurostat (2020c) Employment by age, professional status and NUTS 2 regions (1 000) [lfst_r_lfe2estat]. Retrieved from http://appsso.eurostat.ec.europa.eu/nui/show.do?dataset=lfst_r_lfe2estat\&lang=en

Eurostat (2020d) Gross fixed capital formation by NUTS 2 regions [nama_10r_2gfcf]. Retrieved from https://appsso.eurostat.ec.europa.eu/nui/show.do?dataset=nama_10r_2gfcf\&lang=en

Eurostat (2020e) Employment (thousand persons) by NUTS 3 regions [nama_10r_3empers]. Retrieved from https://appsso.eurostat.ec.europa.eu/nui/show.do?dataset=nama_10r_3empers\&lang=en

Eurostat (2020f) Area by NUTS 3 region [reg_area3]. Retrieved from https://appsso.eurostat.ec.europa. eu/nui/show.do?dataset=reg_area3\&lang=en

Eurostat (2020g) Population aged 25-64 by educational attainment level, sex and NUTS 2 regions (\%) [edat_lfse_04]. Retrieved from https://appsso.eurostat.ec.europa.eu/nui/show.do?dataset=edat_lfse_ $04 \&$ lang=en

Eurostat (2020h) Population on 1 January by five years age group, sex and NUTS 2 region [demo_r_ pjangroup]. Retrieved from http://appsso.eurostat.ec.europa.eu/nui/show.do?dataset=demo_r_pjang roup\&lang=en

Eurostat (2021). Average number of usual weekly hours of work in main job by sex, age and NUTS 2 regions (hours) [lfst_r_lfe2ehour]. Retrieved from https://appsso.eurostat.ec.europa.eu/nui/show.do? dataset=lfst_r_lfe2ehour\&lang=en

Ezcurra R, Rios V (2019) Quality of government and regional resilience in the European Union Evidence from the great recession. Papers Reg Sci 98(3):1267-1290 
Ezcurra R, Pascual P, Rapún M (2007) Spatial inequality in productivity in the European union: sectoral and regional factors. Int Reg Sci Rev 30(4):384-407

Filippetti A, Peyrache A (2015) Labour productivity and technology gap in European regions: a conditional frontier approach. Reg Stud 49(4):532-554

Flegg AT, Tohmo T (2013) Regional input-output tables and the FLQ formula: a case study of Finland. Reg Stud 47(5):703-721

Galbusera L, Giannopoulos G (2018) On input-output economic models in disaster impact assessment. Int J Disaster Risk Reduct 30:186-198

Gardiner B, Fingleton B, Martin R (2020) Regional disparities in labour productivity and the role of capital stoCK. Natl Inst Econ Rev 253:R29-R43

Giacinto VD, Nuzzo G (2006) Explaining labour productivity differentials across Italian regions: the role of socio-economic structure and factor endowments. Pap Reg Sci 85(2):299-320

Giannakis E, Bruggeman A (2017a) Economic crisis and regional resilience: evidence from Greece. Pap Reg Sci 96(3):451-476

Giannakis E, Bruggeman A (2017b) Determinants of regional resilience to economic crisis: a European perspective. Eur Plan Stud 25(8):1394-1415

Giannakis E, Bruggeman A (2020) Regional disparities in economic resilience in the European Union across the urban-rural divide. Reg Stud 54(9):1200-1213

Giannakis E, Bruggeman A, Mamuneas TP, (2021) Regional economic resilience, productivity growth and industrial interconnectedness. Working Paper

Grabner SM, Kitsos A, Incera AC (2020) The role of embeddedness on regional economic resilience. Chapter of the PhD thesis 'Regional Resilience and Diversification: Three Essays on the Role of Local Industrial Structures'. Gran Sasso Science Institute, December 2020. Available at: https://iris. gssi.it/handle/20.500.12571/16026\#.YXUs0J5Bw2w

Holl A (2018) Local employment growth patterns and the great recession: the case of Spain. J Reg Sci 58(4):837-863

Jones LP (1976) The measurement of Hirschmanian linkages. Q J Econ 90(2):323-333

Kitsos A, Carrascal-Incera A, Ortega-Argilés R (2019) The role of embeddedness on regional economic resilience: evidence from the UK. Sustainability 11(14):3800

Klimek P, Poledna S, Thurner S (2019) Quantifying economic resilience from input-output susceptibility to improve predictions of economic growth and recovery. Nat Commun 10(1):1-9

Lagravinese R (2015) Economic crisis and rising gaps North-South: evidence from the Italian regions. Camb J Reg Econ Soc 8(2):331-342

LeSage JP (2014a) Spatial econometric panel data model specification: a Bayesian approach. Spatial Statistics 9:122-145

LeSage JP (2014b) What regional scientists need to know about spatial econometrics. Rev Reg Stud $44: 13-32$

LeSage JP (2015) Software for Bayesian cross section and panel spatial model comparison. J Geogr Syst 17(4):297-310

Levenko N, Oja K, Staehr K (2019) Total factor productivity growth in Central and Eastern Europe before, during and after the global financial crisis. Post-Communist Econ 31(2):137-160

Liu C, He S (2016) Input-output structures of the Australian construction industry. Constr Econ Build 16(2):56-70

Martin R (2012) Regional economic resilience, hysteresis and recessionary shocks. J Econ Geogr 12(1):1-32

Martin R, Sunley P (2015) On the notion of regional economic resilience: conceptualization and explanation. J Econ Geogr 15(1):1-42

Miyamoto H, Takahashi Y (2011) Productivity growth, on-the-job search, and unemployment. J Monet Econ 58(6-8):666-680

Mortensen DT, Pissarides CA (1998) Technological progress, job creation, and job destruction. Rev Econ Dyn 1(4):733-753

OECD (2009) Measuring Capital - OECD Manual. Second Edition. Organization for Economic Co-Operation and Development. Available at: https://www.oecd.org/sdd/productivity-stats/43734711.pdf

Pietroforte R, Gregori T (2003) An input-output analysis of the construction sector in highly developed economies. Constr Manag Econ 21(3):319-327

Pontarollo N, Serpieri C (2020a) Towards regional renewal: a multilevel perspective for the EU. Reg Stud 54(6):754-764 
Pontarollo N, Serpieri C (2020b) Challenges and opportunities to regional renewal in the European Union. Int Reg Sci Rev 44(1):142-169

Rasmussen P (1956) Studies in inter-sectorial relations. Einar Harks, Copenhagen

Song Y, Liu C (2006) The Australian construction linkages in the 1990s. Archit Sci Rev 49(4):408-417

Timmer MP, Dietzenbacher E, Los B, Stehrer R, de Vries GJ (2015) An illustrated user guide to the world input-output database: the case of global automotive production. Rev Int Econ 23(3):575-605

Tohmo T (2004) New developments in the use of location quotients to estimate regional input-output coefficients and multipliers. Reg Stud 38(1):43-54

Tsiapa M, Kallioras D, Tzeremes NG (2018) The role of path-dependence in the resilience of EU regions. Eur Plan Stud 26(6):1099-1120

Van Oort F, de Geus S, Dogaru T (2015) Related variety and regional economic growth in a cross-section of European urban regions. Eur Plan Stud 23(6):1110-1127

Publisher's Note Springer Nature remains neutral with regard to jurisdictional claims in published maps and institutional affiliations. 